\title{
Understanding and overcoming shyness
}

\section{Introduction}

Shyness is a tendency to exhibit withdrawal in social \& work situations. This tendency can be a real obstacle when one wants to relate to others and does not know how to overcome it. It can make one recoil from feared situations, engage in avoidance behaviors and can make one anxious about an outcome. Shy persons may also end up subjecting themselves toun happiness over their inability to relate to others adequately, resulting in self confidence issues and a perception of the self being "less worthier" than others.

\section{Understanding shyness}

Shyness can be traced to an overriding obsession with other's evaluations of one's self, which 'must' be favorable at all costs. The high importance attached to 'how others perceive me' is the crux of shyness problems. When one becomes preoccupied in an attempt to win the approval of significant others in one's life, one may start fearing rejection. Rejection of any kind may then be perceived as something nearly horrible and unacceptable. The high value attached to not being rejected and the meaning given to 'being rejected' can make one hypersensitive to a rejection, thereby wanting to avoid it at all costs.

This becomes self defeating because one fails to understand and accept that rejections are a part of life and they need not be as 'aversive' as they seem. Nor do rejections necessarily mean something lacking within oneself. It means something about the other person. More objectively, it means differential expectations on both ends. Also, the more one wants to avoid a rejection the more one may end up getting rejected, with focus diverted to counting instances of rejection.

What is also self defeating is when a healthy desire to be successful and win the approval of important others escalates to a demand of being able to achieve it at all times, especially with strangers in social gatherings or work setup, in nearly perfect ways by trying to create positive impressions in interactions, thereby naturally failing at the high and unrealistic standards of self assessment enforced upon oneself dogmatically.

Sometimes people are awkward in social situations because of their extreme self assessments, preoccupation with making the "right" moves, constant self evaluation of preventing a "stupid" mistake and so on, instead of just letting the interaction take its course and being okay with even going in unpredictable or unfavorable ways. Little wonder that they end up making a fool of themselves eventually in their quest for perfection by strategizing every move so minutely. It acts as a vicious cycle, repeating itself the more one tries to achieve perfection. One forgets here to keep in mind that as humans, we are bound to make errors and cannot calculate every move for a perfect strike with others! Perhaps such calculations were possible in the gaming arena, where accuracy is even predictable. However in dealing with humans, such predictions and unrealistic expectations of success rates can be extremely self defeating. Besides there is no guarantee, no matter how much one tries to create a positive impression, that the other person in question shall not see it in any other unfavorable way, which is even beyond one's control.
Volume 2 Issue I - 2016

Rajita Ramachandram

Counseling Psychologist, SNDT University, India

Correspondence: Rajita Ramachandram, Counseling

Psychologist, SNDT University, India

Email rajitaformentalhealth@gmail.com

Received: September 24, 2015 | Published: January 08, 2016

\section{Overcoming shyness}

We largely create and maintain our own disturbances in this way by dogmatically sticking to unrealistic expectations of success and approval. What is healthier is a preferential expectation of being able to do well in social setups with an understanding that one may fail sometimes at making the best impression and that is only unavoidable and more importantly quite tolerable!

Restructuring thoughts to realistic expectations of success and approval seeking can help. Questioning why one may need others to think well about one self to be able to think highly about oneself can help. Questioning why one needs to assess one's self in relation to ideals of others can help. Questioning why must one succeed in every interaction and never taste failure can help. Questioning why is failure such a thing to avoid can help. Questioning why one wants to live up to ideals of perfectionism that doesn't exist can help.

Finally learning to unconditionally accept the self for what it is, regardless of whatever traits one may possess [desirable and undesirable] and working to correct the undesirable traits in isolation without attaching them to the self can help. Giving oneself that unconditional acceptance for the person one is, without attaching conditions of self acceptance can help relieve low self esteem issues and the anxiety experienced about approaching others. Being Okay with making mistakes and learning to get better at interactions by pushing yourself into Feared situations can give one an opportunity to figure out how to deal with issues that may prop up or difficult situations, rather than calling yourself imperfect and waiting for that perfection to dawn upon you to start making that first move. Relaxation exercises like breathing and muscle relaxation can also help simultaneously to eliminate the anxiety about 'how well you will fare in an interaction'.

Telling yourself that, "it is not an examination, and the evaluation that others give me is their choice and does not mean I am less worthy when i fail or more worthy when achieve success" can help recreate a set of realistic beliefs about people, self and interactions. Thus by changing how you perceive the event and yourself in relation to the event, by changing what you talk to yourself about the event, you can change how you react to it. Quite a task it may seem to overcome shyness, but certainly advantageous to work at. 


\section{Acknowledgements}

None.

\section{Conflict of interest}

The author declares no conflict of interest. 